\title{
Primary Small Cell Neuroendocrine Carcinoma of the Endometrium: A Cytologically Diagnosed Case with Immunocytochemical, Immunohistochemical, and Electron Microscopic Features
}

\author{
Kentaro Nagata1, Kenji Niwa ${ }^{1 *}$, Sakae Mori², Keigo Kuwabara ${ }^{2}$, Motoki Takenaka $^{3}$, \\ Yoshio Yamaguchi ${ }^{2}$, Kentaro Niwa ${ }^{4,5}$, Takuji Tanaka ${ }^{6}$ \\ ${ }^{1}$ Department of Obstetrics \& Gynecology, Gujo City Hospital, Gujo City, Japan \\ ${ }^{2}$ Section of Laboratory Medicine, Gujo City Hospital, Gujo City, Japan \\ ${ }^{3}$ Department of Obstetrics \& Gynecology, Gifu University School of Medicine, Gifu City, Japan \\ ${ }^{4}$ Department of Obstetrics \& Gynecology, Kizawa Memorial Hospital, Minokamo City, Japan \\ ${ }^{5}$ Present Address: Department of Obstetrics \& Gynecology, University of Fukui Hospital, Yoshida-gun, Fukui Prefecture, Japan \\ ${ }^{6}$ Department of Diagnostic Pathology \& Research Center of Diagnostic Pathology, Gifu Municipal Hospital, Gifu City, Japan \\ Email: *kniwa.gujo913@gmail.com
}

How to cite this paper: Nagata, K., Niwa, K., Mori, S., Kuwabara, K., Takenaka, M., Yamaguchi, Y., Niwa, K. and Tanaka, T. (2020) Primary Small Cell Neuroendocrine Carcinoma of the Endometrium: A Cytologically Diagnosed Case with Immunocytochemical, Immunohistochemical, and Electron Microscopic Features. Open Journal of Pathology, 10, 113-123.

https://doi.org/10.4236/ojpathology.2020.1 04011

Received: July 2, 2020

Accepted: September 11, 2020

Published: September 14, 2020

Copyright $\odot 2020$ by author(s) and Scientific Research Publishing Inc. This work is licensed under the Creative Commons Attribution International License (CC BY 4.0).

http://creativecommons.org/licenses/by/4.0/

(c) (i) Open Access

\begin{abstract}
Endometrial neuroendocrine tumors are rare, accounting less than $1 \%$ of endometrial cancers. They include small cell neuroendocrine carcinoma (NEC) and large cell NEC and usually occur in postmenopausal patients. Although common symptoms include postmenopausal bleeding, most patients are diagnosed at an advanced stage. We report an extremely rare case of small cell NEC developed in the endometrium of a 75 -year-old Japanese woman. This case was initially suspected based on the findings of endometrial cytology: a number of small round malignant cells were present on the endometrial smear specimens. The immunocytochemical and immunohistochemical examinations revealed diffusely cytoplasmic positive reaction of neuron specific enolase (NSE) and partially membranous positive reaction of CD56 in the small cancer cells. They showed PAX-8-positive reaction, but did not express microsatellite instability high. Electron micrography showed several dense-core secretory granules in the cytoplasm of cancer cells. Despite multiple lung metastases, the patient underwent a hysterectomy and salpingo-oophorectomy in order to control excessive genital bleeding. She received six courses of adjuvant chemotherapy based on etoposide and cisplatin, and survived healthy
\end{abstract}


eight months after the first visit without any viability of lung metastases.

\section{Keywords}

SCNEC, Endometrium, NSE, Ultrastructure, Etoposide and Cisplatin Regimen

\section{Introduction}

Neuroendocrine tumors could occur in the female genital organs, but endometrial neuroendocrine tumors are extremely rare. According to the recent WHO classification, they are categorized as low-grade and high-grade neuroendocrine neuroendocrine carcinomas [1]. They are further sub-classified into small-cell and large-cell types [1] [2]. Approximate 100 cases of small-cell neuroendocrine carcinoma (SCNEC) of the endometrium have been reported in the English literatures [3] [4] [5] [6]. SCNEC of the endometrium demonstrates aggressive clinical behavior [1] [4] [5] [7]. Endometrial SCNEC is known to be highly aggressive, because this malignancy is usually diagnosed at advanced stages of the diseases [8]. Furthermore, the prognosis of a pure type of SCNEC is worse, when comparing to that of a mixed type of SCNEC [9].

While most of the SCNECs of the uterine cervix possess mutations in PIK3CA, K-ras, and $p 53$, molecular pathology of the endometrial SCNECs is unknown [10]. Abnormal mismatch repair protein expression was described in a few cases of endometrial SCNECs, but the majority of reported cases have not been included mismatch repair testing [5].

Endometrial cytological examination is a useful and minimally invasive tool for detecting endometrial malignancies, premalignancies, and benign lesions [11]. However, studies on the cytological features of SCNECs of the endometrium are scare [3] [4]. In the present report, we describe cytological, immunocytochemical, immunohistochemical, and ultrastructural features of endometrial SCNEC developed in an old Japanese woman, her clinical course as well.

\section{Case Presentation}

A 75-year-old female, gravida four para four, presented to our hospital with vaginal bleeding for more than three months in 20xy. She had a slight dementia due to previous cerebral bleeding, but did not have chronic diseases, such as hypertension, diabetes. The patient had inserted a soft pessary due to complete prolapse uteri three years ago. She did not visit the gynecologic clinic until then. When the pessary in the vagina was removed, we found that the bleeding came from the uterine cavity. The uterine corpus was enlarged as over new born head size. The endometrial cytology and curettage were performed. On the endometrial cytology specimens, we found atypical cells suggestive of SCNEC [Figure 
1(a)]. Immunocytochemistry revealed that they showed strongly cytoplasmic reactivity against neuron-specific enolase (NSE) [Figure 1(b)]. Endometrial curettage histological specimens were fixed in $10 \%$ neutral buffered formalin, routinely processed, and embedded in paraffin for histopathology and immunohistochemistry. Sections with $3-4 \mu \mathrm{m}$ thickness were made and stained with hematoxylin and eosin (H\&E) for histopathological diagnosis. Immunohistochemistry using twelve different antibodies, such as AE1/AE3 [Dako, 1:50 dilution], NSE (Dako, 1:400 dilution), CD56 (Dako, 1:100 dilution), synaptophysin (Dako, 1:20 dilution), thyroid transcription factor-1 (TTF-1, DAKO, 1:100 dilution), chromogranin (DAKO, 1:1600 dilution), Pax-8 (Protein Tech, 1:100 dilution), MSH2 (Calbiochem, 1:100 dilution), MLH1 (Cell Marque, 1:300 dilution), MSH6 (BD Biosciences, 1:300 dilution), PMS2 (BD Biosciences, 1:125 dilution), and p53 (Dako, 1:100 dilution) was performed. Histopathological examination confirmed SCNEC of the endometrium [Figure 2(a)]. Immunohistochemically, cytoplasm of the tumor cells was strongly positive for NSE [Figure 2(b)]. We also observed nuclear positivity of TTF-1 [Figure 2(c)] and partially cell membranous positivity of CD56 [Figure 2(d)]. Pax-8 [Figure 2(e)], MSH2 [Figure 2(f)], MLH1, MSH6, and PMS2 were all positive in the nucleus of the tumor cells. p53 was partially positive in the tumor cell nuclei.

For electron microscopic examination, small pieces of the formalin-fixed neoplastic tissues were re-fixed in $1 \%$ osmium tetroxide, followed by $0.2 \mathrm{M}$ phosphate buffer, and then embedded in epoxy resin. Ultrathin sections were examined using an electron microscope after staining with uranyl acetate and lead citrate. Ultrastructurally, the cytoplasm of small neoplastic cells contained electron-dense core secretory granules with approximately $500 \mathrm{~nm}$ in diameter (Figure 3) in the cytoplasm.

We determined DNA repair function of the tumor cells using the MSI-IVD Kit (FALCO Biosystems, Kyoto, Japan), which is able to detect MSI-High status within tumor tissues [12]. However, MSI-high could not be detected (Figure 4), as found in immunohistochemistry of MSH2, MLH1, MSH6, and PMS2.
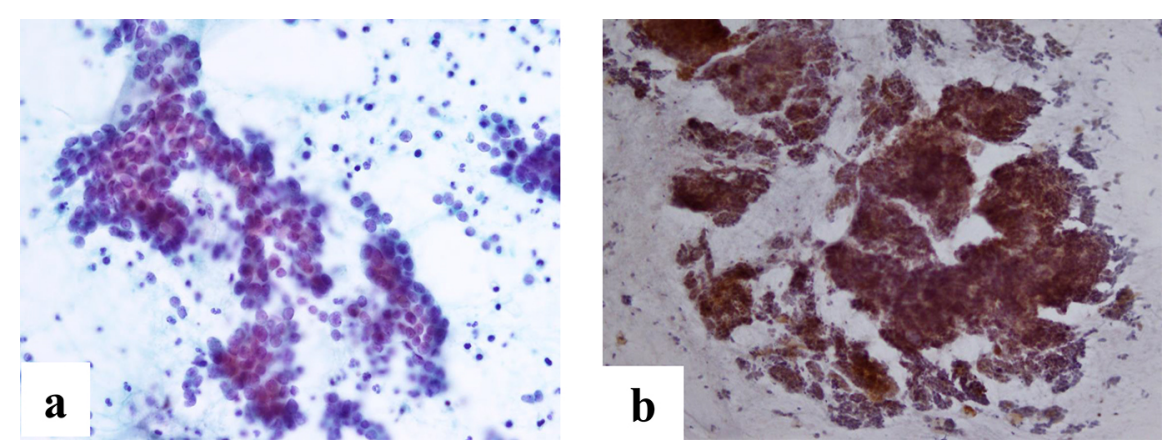

Figure 1. Endometrial cytology. (a) Aggregates of small neoplastic cells with high N/C ratio are present. (b) Neuron-specific enolase (NSE)-immunocytochemistry shows strong cytoplasmic positive reaction in the tumor cells. (a) Papanicolaou stain, $\times 100$; and (b), NSE immunocytochemistry, $\times 100$. 

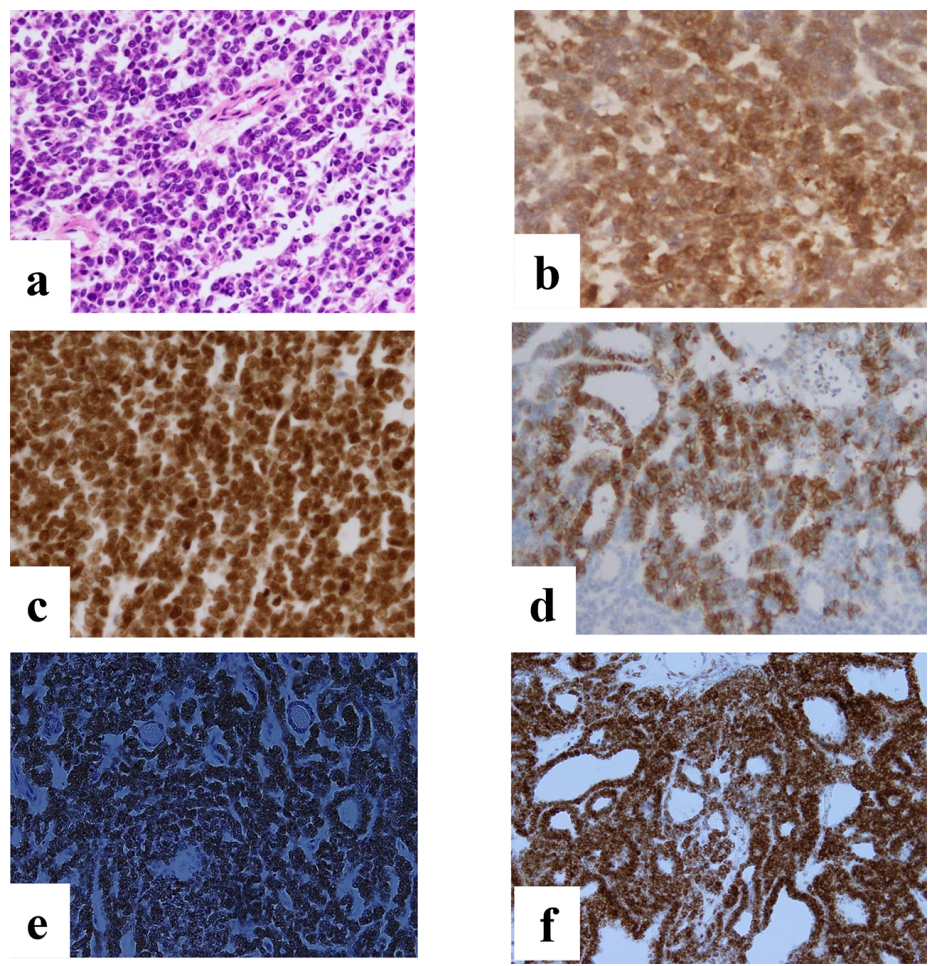

Figure 2. Histopathology and immunohistochemistry of specimens obtained by endometrial curettage. (a) Small neoplastic cells having scant cytoplasm and hyperchromatic round to oval nuclei without visible nucleoli grow in sheets or trabeculas. Immunohistochemical stainings show cytoplasmic positivity of (b) NSE, nuclear positivity of (c) TTF-1, partial membranous positivity of (d) CD56, nuclear positivity of (e) PAX8, and nuclear positivity of (f) MSH2 in the neoplastic cells. (a) H\&E stain, $\times 100$; (b) NSE immunohistochemistry, $\times 100$; (c) TTF-1 immunohistochemistry, $\times 100$; (d) CD56 immunohistochemistry, $\times 100$ ); (e) PAX-8 immunohistochemistry, $\times 80$; and (f) MSH2 immunohistochemistry, $\times 100$.

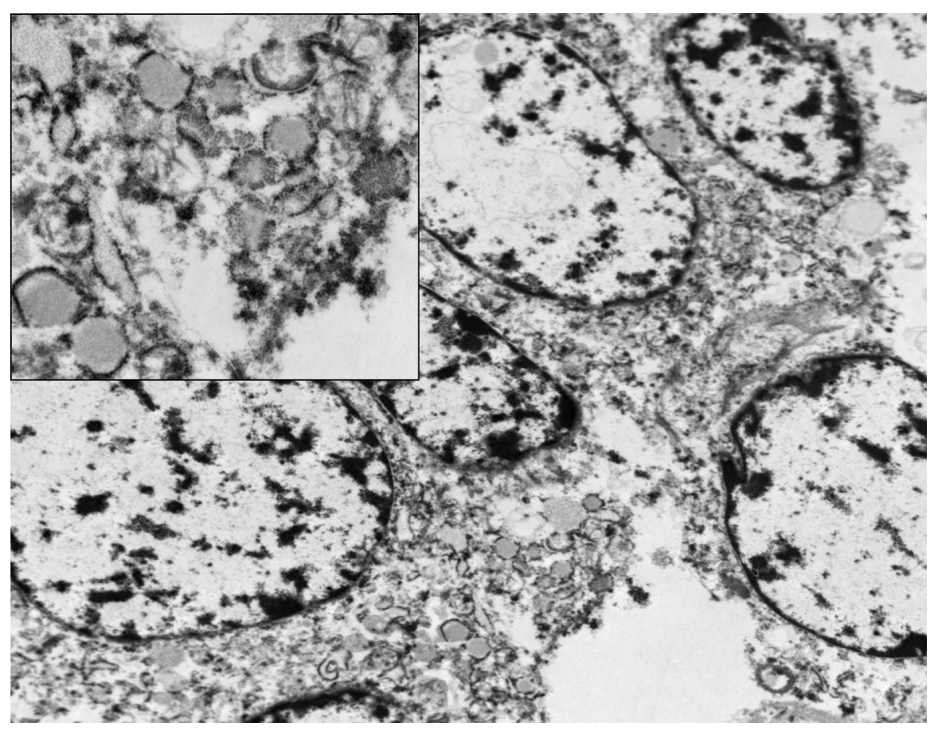

Figure 3. Electron microscopy reveals that small cancer cells have dense-core secretory granules (insert), measuring approximately $500 \mathrm{~nm}$ in diameter, in their cytoplasm. Magnification $\times 13,000$. 


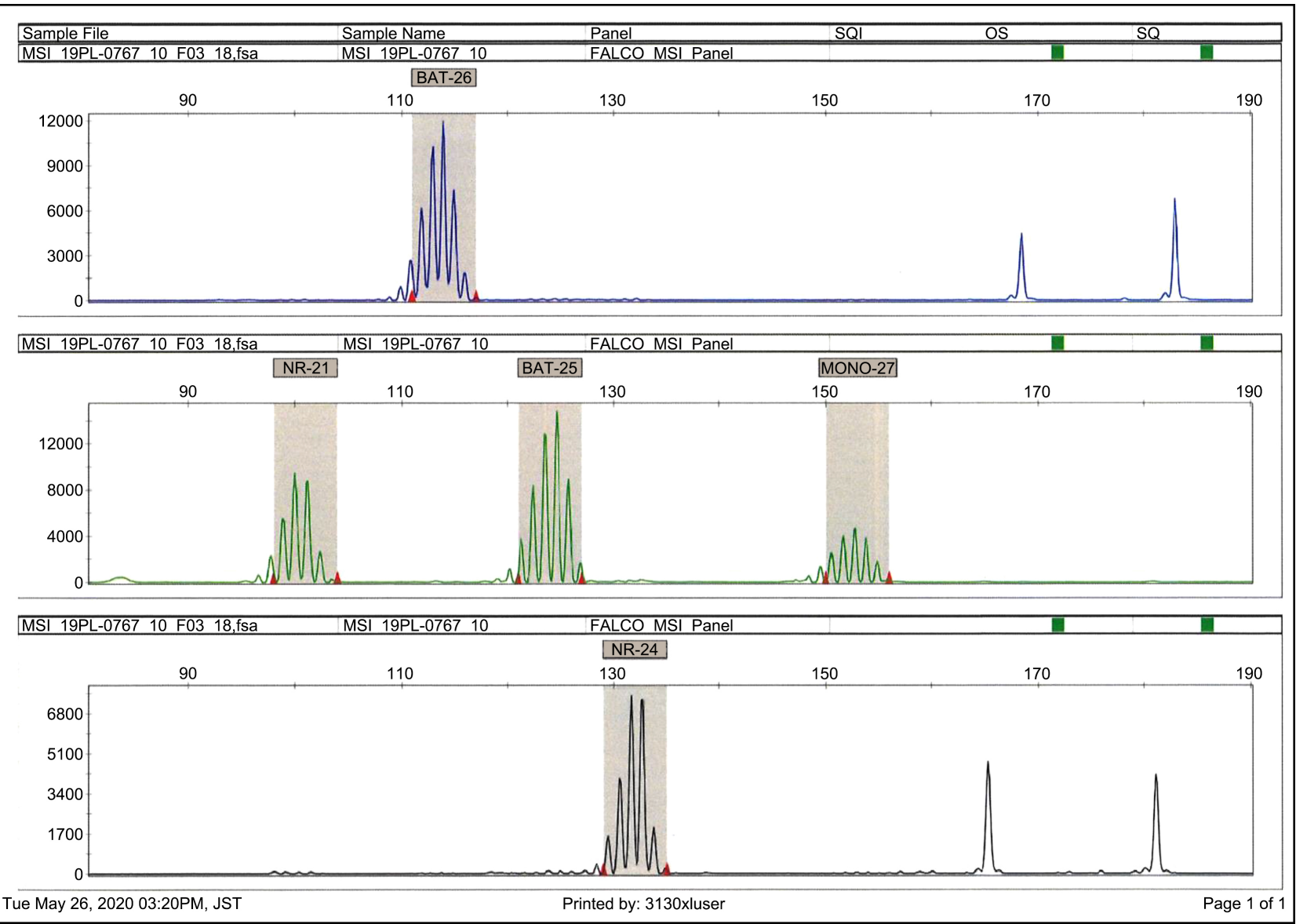

Figure 4. MSI detection pattern. Single symmetric peak was observed in each quasi-monomorphic variation range, suggesting MSI-negative in the tumor cells.

The tumor was suspected to invade to the almost entire wall on magnetic resonance imaging (MRI) (Figure 5), and the whole body computed tomography (CT) scan showed multiple lung metastases [Figure 6(a)]. Therefore, clinical stage was stage IVB. The patient underwent an operation due to uncontrolled genital bleeding two weeks after the first visit. Serum tumor markers, such as CA125, CA19-9, $\alpha$-fetoprotein, and NSE were within normal limits. A hysterectomy and bilateral salpingo-oophorectomy were performed without resection of pelvic lymph nodes, because no metastases in the pelvic lymph nodes were noted on the MRI and CT scans. Small amount of ascites, which did not contain cancer cells was observed during operation. Histopathological examinations revealed confirmed pure SCNEC of the endometrium, and other histologically different neoplasms were not detected. The uterine corpus was almost replaced by the tumor, but the tumor did not invade the serosa (Figure 7) and surrounding tissues, including vagina and lymph nodes. The tumor containing bleeding and necrotic areas in parts was yellowish and relatively soft.

The patient showed uneventful clinical course after the operation. Two weeks after the operation, she started the systemic chemotherapy with etoposide and cisplatin (EP) regimen, which is the adjuvant treatment used for uterine cervical 


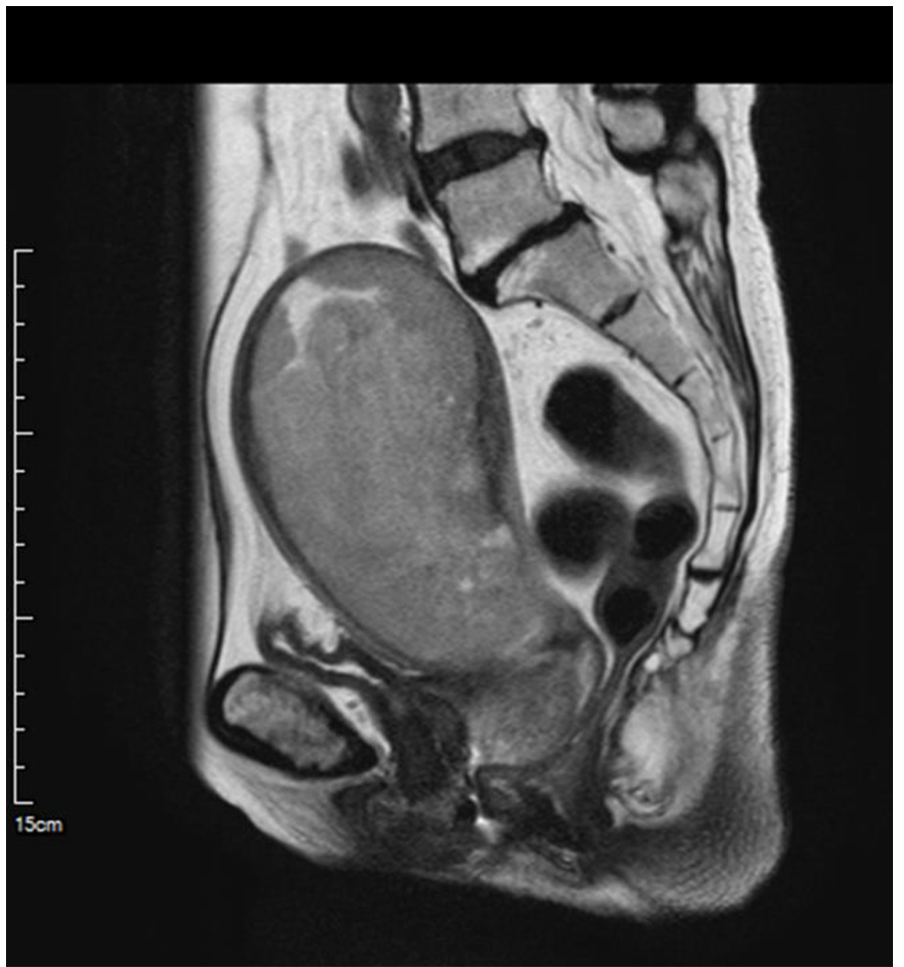

Figure 5. Sagital T2-weighted MR image showing a large tumor with a heterogeneously high intensity, which replaces the cavity of uterine corpus. The tumor measures $110 \mathrm{~mm}$ in major axis.
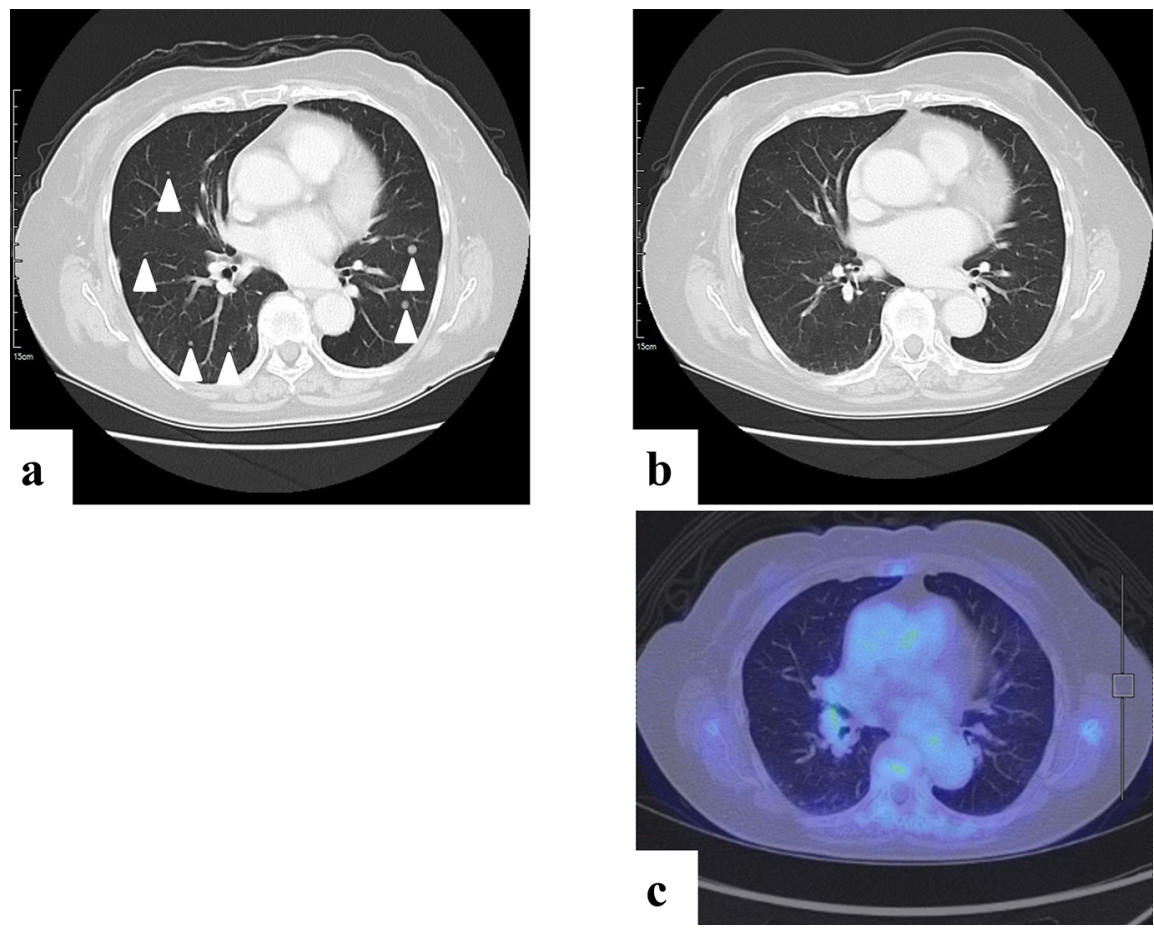

Figure 6. Lung CT and FDG-PET/CT images. (a) Lung CT image before the chemotherapy shows multiple small metastatic lesions (arrow heads). (b) Metastatic lesions are not present on the lung CT image 6-course after the chemotherapy. (c) The FDG-PET/CT shows no enhanced FDG uptake in the lungs. 


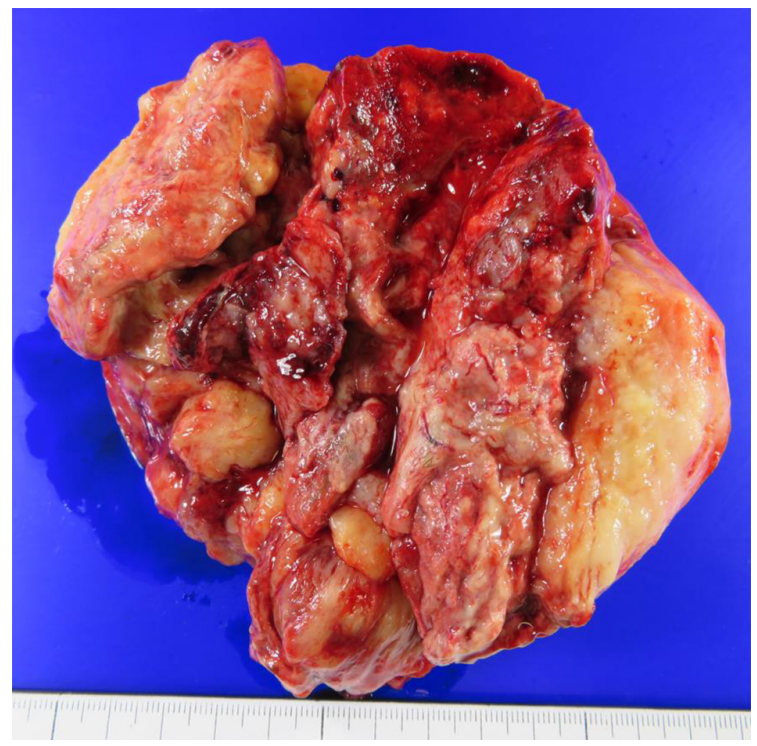

Figure 7. Macroscopic view of the uterus resected surgically. A tumor occupies the endometrial cavity and invades the myometrium, but the serosa is intact. Bleeding and necrotic areas are present in the yellowish and relatively soft tumors.

SCNEC [13] [14]. Because of her higher age, the dosages were reduced: daily etoposide $75 \mathrm{mg} / \mathrm{m}^{2}$ on day 1,2 , and 3 , and cisplatin $40 \mathrm{mg} / \mathrm{m}^{2}$ on day 1 . This regimen is administered for six cycles at 21-day intervals, resulting in disappear of lung metastases [Figure 6(b)] and FDG-ET/CT examination confirmed no viability of tumor cells in the lungs [Figure 6(c)]. The patient survived healthy eight months after the first visit.

\section{Discussion}

The primary SCNEC of the endometrium, which was reported to be approximately 100 cases in the literature is an extremely rare neoplasm [3] [4] [5] [6]. Mean age at the diagnosis is over 60, our case being 75 -year-old. Abnormal or postmenopausal bleeding is the most frequent symptom, as experienced in this case [15]. The cytological and clinicopathological characteristics, including electron microscopic findings and a variety of immunohistochemical features of primary endometrial SCNEC are described. In addition, the management and clinical outcomes of our patient are also presented. We also determined DNA repair function of cancer cells using the MSI-IVD Kit and immunohistochemistry with primary antibodies, such as MSH2, MLH1, MSH6, and PMS2. However, cancer cells did not have DNA repair dysfunction.

The endometrial SCNEC is reported to have aggressive clinical behavior $[1,7]$. Five-year survival rate of stage IVB in ENCs was found to be $12.0 \%(0.7 \%$ $40.8 \%)$, while that of endometrioid adenocarcinoma was $27.7 \%(25.2 \%-30.3 \%)$ [6]. The aggressive surgical resection and adjuvant chemotherapy with or without radiotherapy appeared to be responsible for the favorable outcomes. Our 
case was histopathologically a pure type of endometrial SCNEC. When compared to a mixed type of endometrial SCNEC, prognosis of a pure type was reported to be worse [9]. Treatment strategies for endometrial NEC are not standardized [6], and most cases of endometrial SCNEC include platinum-based chemotherapy with etoposide or paclitaxel [6] [15], as performed in the small cell lung cancers. In our case, reductive surgery and following EP chemotherapy suppressed recurrence and lung metastases.

There are a few reports on the cytological features of endometrial SCNEC [3] [4]. The characteristics of cytological include the presence of single or small nests of neoplastic cells with a high nuclear/cytoplasmic ratio, round to oval nuclei containing coarse chromatin in necrotic backgrounds [3], corresponding to the typical cytological features of lung SCNEC [16]. As reported [17], immunocytochemistry using NSE was useful for the cytological diagnosis of endometrial SCNEC in this case.

For accurate histopathological diagnosis of NEC, neuroendocrine markers, including NSE, chrogranin A, synaptophsin, Leu-7, and CD56 are essential [18] [19]. All NECs expressed at least one neuroendocrine marker [1] [5] [7]. In this case, the cancer cells showed cytoplasmic positive reaction of NSE and partially cell membranous positivity of CD56. Electron microscopic findings showing cytoplasmic electron-dense secretory core granules in cancer cells confirmed neuroendocrine features of the neoplasm in this case [20].

Although a transcription factor, PAX-8, in the regulation of organogenesis of the thyroid gland, kidney, and Müllerian system, is commonly expressed in the nuclei of most endometrial adenocarcinoma cells [21], approximate $30 \%$ of endometrial NECs were immunohistochemically positive for PAX-8 [5]. Pocrnich et al. reported that the NECs tend to be PAX- 8 negative and may be associated with microsatellite instability [5]. However, their cases were large cell NECs. In our case, PAX- 8 was positive and p53 was focally positive in the cancer cell nuclei. It is known that nuclear expression of PAX-8 and p53 is well-correlated in the endometrial carcinomas regardless histopathological types such as endometrioid and non-endometrioid types. Pax- 8 positivity correlating with p53 expression might be one of useful prognostic parameters [22]. Most commonly observed mutations were reported to be PIK3CA, $K$-ras, and $p 53$ in the SCNEC of the uterine cervix [23] [24] [25], the molecular alterations in the endometrial SCNEC were not well-understood because of its rarity [10]. Nuclear p53 was focally positive in the tumor cells, suggesting the importance of p53 mutation for the development of SCNEC in our case.

\section{Conclusion}

We report here an extremely rare case of primary endometrial SCNEC initially diagnosed by endometrial cytology. Immunocytochemical, immunohistochemi$\mathrm{cal}$, and ultrastructural examinations confirmed the diagnosis. Reductive surgery and EP-chemotherapy were effective for the treatment. 


\section{Acknowledgements}

We thank the editor and reviewers for the constructive comments, which helped us to improve the manuscript. This case report was approved by the patient documental consent.

\section{Authors' Contributions}

\begin{tabular}{cccccccccc}
\hline Authors' contributions & KNi & KNa & SM & KK & MM & MT & YY & KNi & TT \\
\hline Research concept and design & y & n & n & n & n & n & n & y & n \\
Collection and/or assembly of data & y & y & y & n & n & y & y & y & n \\
Data analysis and interpretation & y & y & y & y & y & y & y & y & n \\
Writing the article & y & n & n & n & n & n & n & n & y \\
Critical revision of the article & y & n & n & n & n & n & n & n & y \\
Final approval of the article & y & y & y & y & y & y & y & y & y \\
\hline
\end{tabular}

\section{Conflicts of Interest}

The authors declare no conflicts of interest regarding the publication of this paper.

\section{References}

[1] Zaino, R., Carinelli, S.G., Ellenson, L.H., Eng, C., Katabuchi, H., Konishi, I., Lax, S., Matias-Guiu, X., Mutter, G.L., Peters, W.A.I., Sherman, M.E., Shih, I.-M., Soslow, R. and Stewart, C.J.R. (2014) Epithelial Tumours and Precursors. In: Kurman, R., Carcangiu, M.L., Herrington, C.S. and Young, R.H., Eds., WHO Classification of Tumours of Female Reproductive Organs, IARC, Lyon, 125-135.

[2] Oliva, E., Wilbur, D.C., Sebire, N.J. and Soslow, R.A. (2020) Miscelllaneous and Metastatic Malignancies. In: Silverberg, S.G., Ed., Tumors of the Uterine Corpus and Trophoblastic Diseases, American Registry of Pathology, Arlington, 421-443.

[3] Ebisu, Y., Ishida, M., Okano, K., Sandoh, K., Mizokami, T., Kita, M., Okada, H. and Tsuta, K. (2019) Small-Cell Neuroendocrine Carcinoma in Directly Sampled Endometrial Cytology: A Monocentric Retrospective Study of Six Cases. Diagnostic Cytopathology, 47, 1297-1301. https://doi.org/10.1002/dc.24298

[4] Ishida, M., Iwamoto, N., Nakagawa, T., Kaku, S., Iwai, M., Kagotani, A., Takahashi, K., Murakami, T. and Okabe, H. (2014) Small Cell Carcinoma of the Endometrium: A Case Report with Emphasis on the Cytological Features. International Journal of Clinical and Experimental Pathology, 7, 3332-3337.

[5] Pocrnich, C.E., Ramalingam, P., Euscher, E.D. and Malpica, A. (2016) Neuroendocrine Carcinoma of the Endometrium: A Clinicopathologic Study of 25 Cases. The American Journal of Surgical Pathology, 40, 577-586. https://doi.org/10.1097/PAS.0000000000000633

[6] Schlechtweg, K., Chen, L., St Clair, C.M., Tergas, A.I., Khoury-Collado, F., Hou, J.Y., Melamed, A., Neugut, A.I., Hershman, D.L. and Wright, J.D. (2019) Neuroendocrine Carcinoma of the Endometrium: Disease Course, Treatment, and Outcomes. Gynecologic Oncology, 155, 254-261. https://doi.org/10.1016/j.ygyno.2019.09.004 
[7] Rouzbahman, M. and Clarke, B. (2013) Neuroendocrine Tumors of the Gynecologic Tract: Select Topics. Seminars in Diagnostic Pathology, 30, 224-233. https://doi.org/10.1053/j.semdp.2013.06.007

[8] Huntsman, D.G., Clement, P.B., Gilks, C.B. and Scully, R.E. (1994) Small-Cell Carcinoma of the Endometrium. A Clinicopathological Study of Sixteen Cases. The American Journal of Surgical Pathology, 18, 364-375. https://doi.org/10.1097/00000478-199404000-00005

[9] Matsumoto, H., Shimokawa, M., Nasu, K., Shikama, A., Shiozaki, T., Futagami, M., Kai, K., Nagano, H., Mori, T., Yano, M., Sugino, N., Fujimoto, E., Yoshioka, N., Nakagawa, S., Shimada, M., Tokunaga, H., Yamada, Y., Tsuruta, T., Tasaki, K., Nishikawa, R., Kuji, S., Motohashi, T., Ito, K., Yamada, T. and Teramoto, N. (2019) Clinicopathologic Features, Treatment, Prognosis and Prognostic Factors of Neuroendocrine Carcinoma of the Endometrium: A Retrospective Analysis of 42 Cases from the Kansai Clinical Oncology Group/Intergroup Study in Japan. Journal of Gynecological Oncology, 30, e103. https://doi.org/10.3802/jgo.2019.30.e103

[10] Patibandla, J.R., Fehniger, J.E., Levine, D.A. and Jelinic, P. (2018) Small Cell Cancers of the Female Genital Tract: Molecular and Clinical Aspects. Gynecologic Oncology, 149, 420-427. https://doi.org/10.1016/j.ygyno.2018.02.004

[11] Kobayashi, T.K., Norimatsu, Y. and Buccoliero, A.M. (2010) Cytology of the Body of the Uterus. In: Gray, W. and Kocjan, G., Eds., Diagnostic Cytopathology, Elsevier, Amsterdam, 689-919. https://doi.org/10.1016/B978-0-7020-3154-0.00026-0

[12] Buhard, O., Cattaneo, F., Wong, Y.F., Yim, S.F., Friedman, E., Flejou, J.F., Duval, A. and Hamelin, R. (2006) Multipopulation Analysis of Polymorphisms in Five Mononucleotide Repeats Used to Determine the Microsatellite Instability Status of Human Tumors. Journal of Clinical Oncology, 24, 241-251. https://doi.org/10.1200/JCO.2005.02.7227

[13] Tempfer, C.B., Tischoff, I., Dogan, A., Hilal, Z., Schultheis, B., Kern, P. and Rezniczek, G.A. (2018) Neuroendocrine Carcinoma of the Cervix: A Systematic Review of the Literature. BMC Cancer, 18, Article No. 530. https://doi.org/10.1186/s12885-018-4447-x

[14] Yin, Z.M., Yu, A.J., Wu, M.J., Fang, J., Liu, L.F., Zhu, J.Q. and Yu, H. (2015) Effects and Toxicity of Neoadjuvant Chemotherapy Preoperative Followed by Adjuvant Chemoradiation in Small Cell Neurdendocrine Cervical Carcinoma. European Journal of Gynaecological Oncology, 36, 326-329.

[15] Koo, Y.J., Kim, D.Y., Kim, K.R., Kim, J.H., Kim, Y.M., Kim, Y.T. and Nam, J.H. (2014) Small Cell Neuroendocrine Carcinoma of the Endometrium: A Clinicopathologic Study of Six Cases. Taiwanese Journal of Obstetrics \& Gynecology, 53, 355-359. https://doi.org/10.1016/j.tjog.2013.05.006

[16] Proca, D., Keyhani-Rofagha, S., Copeland, L.J. and Hameed, A. (1998) Exfoliative Cytology of Neuroendocrine Small Cell Carcinoma of the Endometrium. A Report of Two Cases. Acta Cytologica, 42, 978-982. https://doi.org/10.1159/000331980

[17] Inoue, M., Ueda, G. and Nakajima, T. (1985) Immunohistochemical Demonstration of Neuron-Specific Enolase in Gynecologic Malignant Tumors. Cancer, 55, 1686-1690. https://doi.org/10.1002/1097-0142(19850415)55:8<1686::AID-CNCR2820550813>3. $\underline{0 . \mathrm{CO} ; 2-\mathrm{H}}$

[18] Albores-Saavedra, J., Martinez-Benitez, B. and Luevano, E. (2008) Small Cell Carcinomas and Large Cell Neuroendocrine Carcinomas of the Endometrium and Cervix: Polypoid Tumors and Those Arising in Polyps May Have a Favorable Prognosis. International Journal of Gynecological Pathology, 27, 333-339.

https://doi.org/10.1097/PGP.0b013e31815de006 
[19] van Hoeven, K.H., Hudock, J.A., Woodruff, J.M. and Suhrland, M.J. (1995) Small Cell Neuroendocrine Carcinoma of the Endometrium. International Journal of $G y$ necological Pathology, 14, 21-29. https://doi.org/10.1097/00004347-199501000-00005

[20] Tsujioka, H., Eguchi, F., Emoto, M., Hachisuga, T., Kawarabayashi, T. and Shirakawa, K. (1997) Small-Cell Carcinoma of the Endometrium: An Immunohistochemical and Ultrastructural Analysis. Journal of Obstetrics and Gynaecology Research, 23, 9-16. https://doi.org/10.1111/j.1447-0756.1997.tb00798.x

[21] Ordonez, N.G. (2012) Value of PAX 8 Immunostaining in Tumor Diagnosis: A Review and Update. Advances in Anatomic Pathology, 19, 140-151. https://doi.org/10.1097/PAP.0b013e318253465d

[22] Brunner, A.H., Riss, P., Heinze, G., Meltzow, E. and Brustmann, H. (2011) Immunoexpression of PAX 8 in Endometrial Cancer: Relation to High-Grade Carcinoma and p53. International Journal of Gynecological Pathology, 30, 569-575. https://doi.org/10.1097/PGP.0b013e31821ac6c3

[23] Ishida, G.M., Kato, N., Hayasaka, T., Saito, M., Kobayashi, H., Katayama, Y., Sasou, S., Yaegashi, N., Kurachi, H. and Motoyama, T. (2004) Small Cell Neuroendocrine Carcinomas of the Uterine Cervix: A Histological, Immunohistochemical, and Molecular Genetic Study. International Journal of Gynecological Pathology, 23, 366-372. https://doi.org/10.1097/01.pgp.0000139637.01977.61

[24] Mannion, C., Park, W.S., Man, Y.G., Zhuang, Z., Albores-Saavedra, J. and Tavassoli, F.A. (1998) Endocrine Tumors of the Cervix: Morphologic Assessment, Expression of Human Papillomavirus, and Evaluation for Loss of Heterozygosity on 1p, 3p, 11q, and 17p. Cancer, 83, 1391-1400.

https://doi.org/10.1002/(SICI)1097-0142(19981001)83:7<1391::AID-CNCR17>3.0.C O;2-\#

[25] Wistuba II, Thomas, B., Behrens, C., Onuki, N., Lindberg, G., Albores-Saavedra, J. and Gazdar, A.F. (1999) Molecular Abnormalities Associated with Endocrine Tumors of the Uterine Cervix. Gynecologic Oncology, 72, 3-9.

https://doi.org/10.1006/gyno.1998.5248 